ACCEPTED MANUSCRIPT

\title{
Technical Note: Comparison of metal-on-metal hip simulator wear measured by gravimetric, CMM and optical profiling methods
}

To cite this article before publication: Larry Russell Alberts et al 2018 Surf. Topogr.: Metrol. Prop. in press https://doi.org/10.1088/2051$\underline{672 X / a a a 518}$

\author{
Manuscript version: Accepted Manuscript \\ Accepted Manuscript is "the version of the article accepted for publication including all changes made as a result of the peer review process, \\ and which may also include the addition to the article by IOP Publishing of a header, an article ID, a cover sheet and/or an 'Accepted \\ Manuscript' watermark, but excluding any other editing, typesetting or other changes made by IOP Publishing and/or its licensors" \\ This Accepted Manuscript is @ 2018 IOP Publishing Ltd.
}

During the embargo period (the 12 month period from the publication of the Version of Record of this article), the Accepted Manuscript is fully protected by copyright and cannot be reused or reposted elsewhere.

As the Version of Record of this article is going to be / has been published on a subscription basis, this Accepted Manuscript is available for reuse under a CC BY-NC-ND 3.0 licence after the 12 month embargo period.

After the embargo period, everyone is permitted to use copy and redistribute this article for non-commercial purposes only, provided that they adhere to all the terms of the licence https://creativecommons.org/licences/by-nc-nd/3.0

Although reasonable endeavours have been taken to obtain all necessary permissions from third parties to include their copyrighted content within this article, their full citation and copyright line may not be present in this Accepted Manuscript version. Before using any content from this article, please refer to the Version of Record on IOPscience once published for full citation and copyright details, as permissions will likely be required. All third party content is fully copyright protected, unless specifically stated otherwise in the figure caption in the Version of Record.

View the article online for updates and enhancements. 
TITLE

Technical Note: Comparison of Metal-on-Metal Hip Simulator Wear Measured by Gravimetric, CMM and Optical Profiling Methods

L. Russell Alberts ${ }^{* 1,4}$, Vanesa Martinez-Nogues ${ }^{1,5}$, Richard Baker Cook ${ }^{1}$, Christian Maul ${ }^{2}$, Paul Bills $^{3}$, R. Racasan ${ }^{3}$, Martin Stolz ${ }^{1}$, and Robert J. K. Wood ${ }^{1}$ ${ }^{1}$ University of Southampton, Southampton, UK; ${ }^{2}$ RedLux Ltd, Chandler's Ford, UK; ${ }^{3}$ University of Huddersfield, Huddersfield, UK; ${ }^{4}$ Alberts BioMechanics, LLC, Omaha, NE; ${ }^{5}$ now at CIDETEC, Donostia- San Sebastian, Spain

Address, phone \& email address of corresponding author 4426 S $187^{\text {th }}$ St., Omaha, NE 68135 USA (402)894-2978 L.R.Alberts@soton.ac.uk or Lra1951@msn.com

Running title: Hip Simulator Wear Measurement Methods 


\section{AUTHORS' CONTRIBUTIONS}

LRA conceived and designed the experiments. LRA, VM, PB and RR performed the experiments. $\mathrm{RBC}$ and $\mathrm{CM}$ trained and assisted in the data gathering. LRA drafted the manuscript and all the authors critically reviewed and approved the submitted and final version.

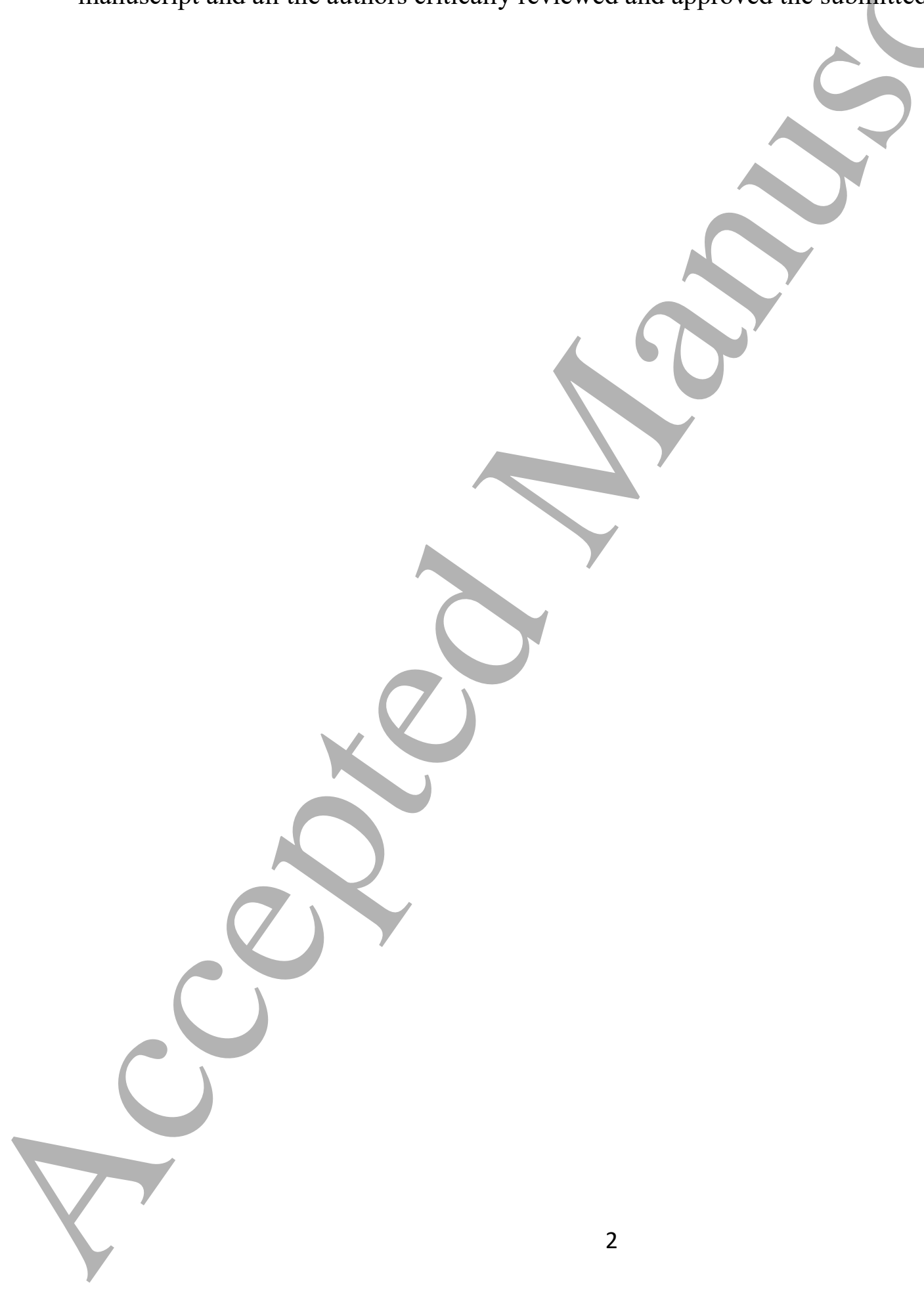


ABSTRACT

Simulation of wear in artificial joint implants is critical for evaluating implant designs and materials. Traditional protocols employ the gravimetric method to determine the loss of material by measuring the weight of the implant components before and after various test intervals and after the completed test. However, the gravimetric method cannot identify the location, area coverage or maximum depth of the wear and it has difficulties with proportionally small weight changes in relatively heavy implants. In this study, we compare the gravimetric method with two geometric surface methods; an optical light method (RedLux) and a coordinate measuring method (CMM). We tested ten Adept hips in a simulator for 2 million cycles (MC). Gravimetric and optical methods were performed at $0.33,0.66,1.00,1.33$ and $2 \mathrm{MC}$. CMM measurements were done before and after the test. A high correlation was found between the gravimetric and optical methods for both heads $\left(\mathrm{R}^{2}=0.997\right)$ and for cups $\left(\mathrm{R}^{2}=0.96\right)$. Both geometric methods (optical and CMM) measured more volume loss than the gravimetric method (for the heads, $\mathrm{p}=0.004$ (optical) and $\mathrm{p}=0.08(\mathrm{CMM})$; for the cups $\mathrm{p}=0.01$ (optical) and $\mathrm{p}=$ $0.003(\mathrm{CMM}))$. Two cups recorded negative wear at $2 \mathrm{MC}$ by the gravimetric method but none did by either the optical method or by CMM. The geometric methods were prone to confounding factors such as surface deformation and the gravimetric method could be confounded by protein absorption and backside wear. Both of the geometric methods were able to show the location, area covered and depth of the wear on the bearing surfaces, and track their changes during the test run; providing significant advantages to solely using the gravimetric method. 


\section{INTRODUCTION}

Wear simulation tests are used as a validation of new hip and knee implant designs and material combinations. They are essential for the continued improvement of orthopeadic implants. The critical measurement in these simulations is the weight change in the implant component that is then converted to a volume amount. In many modern hard-on-hard material combinations (such as ceramic-on-ceramic or metal-on-metal), the wear loss may be under 0.01 milligram for an implant that weighs about $200 \mathrm{~g}^{1}$ (less than one part per 20 million); a proportional weight change amount difficult or nearly impossible to reliably measure with even expensive balances. Yet, even tiny amounts of metal wear may lead to dangerous blood levels of cobalt and chromium ions, pseudotumors and adverse tissue reactions that promote a premature failure of the implant in the patient. ${ }^{2,3,4,5}$

Measurement of the gross weight change provides no detail on where the change is occurring. Loss of material could change the clearance between the head and cup of an implant and a change in clearance could undermine its tribological properties ${ }^{6}$ by shifting from fluid film lubrication to the regime of mixed film lubrication. The fluid regime can also be adversely affected by roughening of the bearing surface which would affect the film thickness ${ }^{7}$ and cause more wear. Wear in hard on soft knee implants has been shown to change their kinematic properties. ${ }^{8}$ Wear that is drifting toward the edge of the cup may suddenly accelerate at the edge producing particularly catastrophic "edge wear." Wear has also been shown to occur on the backside of the implant and produce interface problems with bone, cement or other modular components. 
The optical method can scan the entire bearing surface of a hip or knee component in under 5 minutes and the CMM method in about 45 minutes. Rapid scanning speeds may make it feasible for surface measurements to be collected along with each weight measurement.

Researchers could then track the changes of the wear scar and perhaps anticipate future catastrophic events such as edge loading.

Surface measurement methods such as CMM and out of roundness (OOR) have been previously used to evaluate MoM retrievals ${ }^{11}$ and provide valuable information on their failure and wear mechanisms and to validate simulation models. Such in vivo methods lack the precision of in vitro simulation measurements since there is never an available scan of the implant surface prior to implantation.

Here we compare the estimates of wear by the traditional gravimetric method with a noncontact 3D confocal white light optical profiling method and by a contact coordinate measuring method (CMM) on ten $50 \mathrm{~mm}$ metal-on-metal resurfacing implants for up to $2 \mathrm{MC}$. The gravimetric and optical measurements were repeated at $0.33,0.66,1.00,1.33$ and $2 \mathrm{MC}$. The CMM measurements were performed on the hips prior to the test and at the end of the test. Both the cups and the heads were measured by all three methods. 


\section{METHODS}

A wear simulation test was performed on ten 50-mm Adept (MatOrtho, Leatherhead, UK) resurfacing hips for two million cycles (MC) using a Prosim hip simulator (Simulation Solutions, Stockport, UK). Adept hips are metal-on-metal resurfacing implants composed of ASTM F75 CoCrMo alloy. ${ }^{12}$ They had an average clearance of $97 \mu \mathrm{m}$. The test was conducted at a controlled temperature of $37 \pm 2^{\circ} \mathrm{C}$, at a frequency of $1.0 \mathrm{~Hz}$ and with dual peak strikes of 3 $000 \mathrm{~N}$, mid-food load of $2350 \mathrm{~N}$ and swing phase of $350 \mathrm{~N}$ all about $\pm 10 \%$. The simulator kinematics for flexion/extension was $30^{\circ} /-15^{\circ}$ and internal/external rotation $10^{\circ} /-10^{\circ}$. The lubricant was composed of $25 \%$ newborn fetal bovine calf serum with an undiluted protein content of $62 \mathrm{~g} / 1$. One hip was removed from the correlation data after $0.67 \mathrm{MC}$ after its lubricant container failed.

Wear loss was estimated by the gravimetric method described in ASTM F1714 ${ }^{13}$ (Genius balance, Model ME235S, Sartorius AG, Germany), by a non-contact 3D optical profiling method (RedLux Ltd., Chandler's Ford, UK) after every 1/3 million cycles up to $1.33 \mathrm{MC}$ then again at $2.00 \mathrm{MC}$ and also by the CMM method prior to the run and at 2.00 MC.

The RedLux Artificial Hip Profiler uses chromatic aberration of white light (not laser) to determine the distance to a surface with a resolution in the radial direction of $20 \mathrm{~nm} .{ }^{14}$ An automated mechanized system was used to produce a spiral pattern of measurements points. A baseline profile was established for each component prior to the run. At each measurement, the data from the non-wear region was fit to a sphere and a Boolean subtraction was performed from the baseline scan. The volume of wear, the total wear area and the maximum depth of wear were determined. 
The CMM method used in this study utilizes a physical probe that contacts the surface and creates a polar grid of points on the bearing surface of the head or cup. This methodology has been previously used and validated in a number of studies ${ }^{15,16,17}$ and is in agreement with ASTM guidance in this area. ${ }^{18}$ The exported data was analyzed in accordance with the previously published method which applies an intelligent iterative least squares fit to determine the component's unworn geometry. Data collected after the $2 \mathrm{MC}$ wear cycle run was used to determine the volume of wear, the total wear area and the maximum depth of wear.

Paired Student's t-tests and Pearson's correlation coefficient were used for data analysis and was considered significant at $\mathrm{p}<0.05$. 


\section{RESULTS}

After two million cycles, the cup wear varied from 0.63 to $54.7 \mathrm{~mm}^{3}$ as measured by the optical method, from 0.58 to 55.14 as measured by the CMM method and from -0.98 to 41.8 $\mathrm{mm}^{3}$ as measured by the gravimetric method. At the end of the test, the wear on the heads varied from 0.99 to $62.14 \mathrm{~mm}^{3}$ as measured by the optical method, from 1.13 to 65.77 as measured by CMM and 0.43 to $58.20 \mathrm{~mm}^{3}$ as measured by the gravimetric method. Our combined (head and cup) gravimetric wear rate ranged from $0.32 \mathrm{~mm}^{3} / \mathrm{MC}$ to $50.0 \mathrm{~mm}^{3} / \mathrm{MC}$ with an average of 16.1 $\mathrm{mm}^{3} / \mathrm{MC}(\mathrm{n}=9)$. Three stations produced less than $3 \mathrm{~mm}^{3} / \mathrm{MC}$ wear. The color of the spent lubricant ranged from black in the high-wear stations to light tan in the low wear stations. Basic accuracy differences and advantages and disadvantages of the three methods are tabulated in Table 1. 
Table 1. Comparison of the three methods.

\begin{tabular}{|c|c|c|c|}
\hline & Gravimetric & CMM & Optical \\
\hline Methodology & Weight of specimens & Direct contact & $\begin{array}{c}\text { White light, no physical } \\
\text { contact }\end{array}$ \\
\hline $\begin{array}{l}\text { Resolution in radial } \\
\text { direction or resolution } \\
\text { and reproducibility in } \\
\text { weight measurement }\end{array}$ & $\begin{array}{c}\text { Display readout to } 0.01 \\
\text { mg with a standard } \\
\text { deviation of } 0.026 \mathrm{mg} \\
\text { when repeated at } 18 \\
\text { time periods over a two } \\
\text { day period for weights } \\
\text { of } 177 \mathrm{~g}\end{array}$ & $100 \mathrm{~nm}$ & \\
\hline Surface points sampled & - & $\sim 150,000$ & $\sim 20,800$ \\
\hline Advantages & Standard method & $\begin{array}{c}\text { Can measure the wear: } \\
\text { Area } \\
\text { Shape } \\
\text { Maximum depth }\end{array}$ & $\begin{array}{c}\text { Can measure the wear: } \\
\text { Area } \\
\text { Shape } \\
\text { Maximum depth }\end{array}$ \\
\hline Disadvantages & $\begin{array}{c}\text { Effected by } \\
\text { protein absorption on } \\
\text { implants and } \\
\text { backside wear }\end{array}$ & $\begin{array}{l}\text { Cannot distinguish } \\
\text { between wear and } \\
\text { surface deformation }\end{array}$ & $\begin{array}{l}\text { Cannot distinguish } \\
\text { between wear and } \\
\text { surface deformation }\end{array}$ \\
\hline
\end{tabular}


At two million cycles, the optical method measured wear scar areas largely circular to elliptical in shape ranging from $324 \mathrm{~mm}^{2}$ to $1802 \mathrm{~mm}^{2}$ on the heads and from $201 \mathrm{~mm}^{2}$ to 1646 $\mathrm{mm}^{2}$ on the cups. The maximum wear depth ranged from $5.1 \mu \mathrm{m}$ to $73.4 \mu \mathrm{m}$ on the heads and from $2.7 \mu \mathrm{m}$ to $101.9 \mu \mathrm{m}$ on the cups.

\section{Optical measurements done at all weighing intervals $(n=47)$}

As Figures 1 and 2 show, a high correlation was found between the gravimetric and optical methods for both heads $\left(\mathrm{R}^{2}=0.997\right)$ and for cups $\left(\mathrm{R}^{2}=0.96\right)$. The progression of the wear scar on a moderate wear head that was in the middle range of volume loss is shown in Figure 3 and on a low wear head in Figure 4.

Tribofilm, a hard carbon-rich adherent film that has been attributed to improving friction and wear properties ${ }^{19}$ was observed on most bearing surfaces visually and was identifiable on the optical scans on most bearing surfaces. 


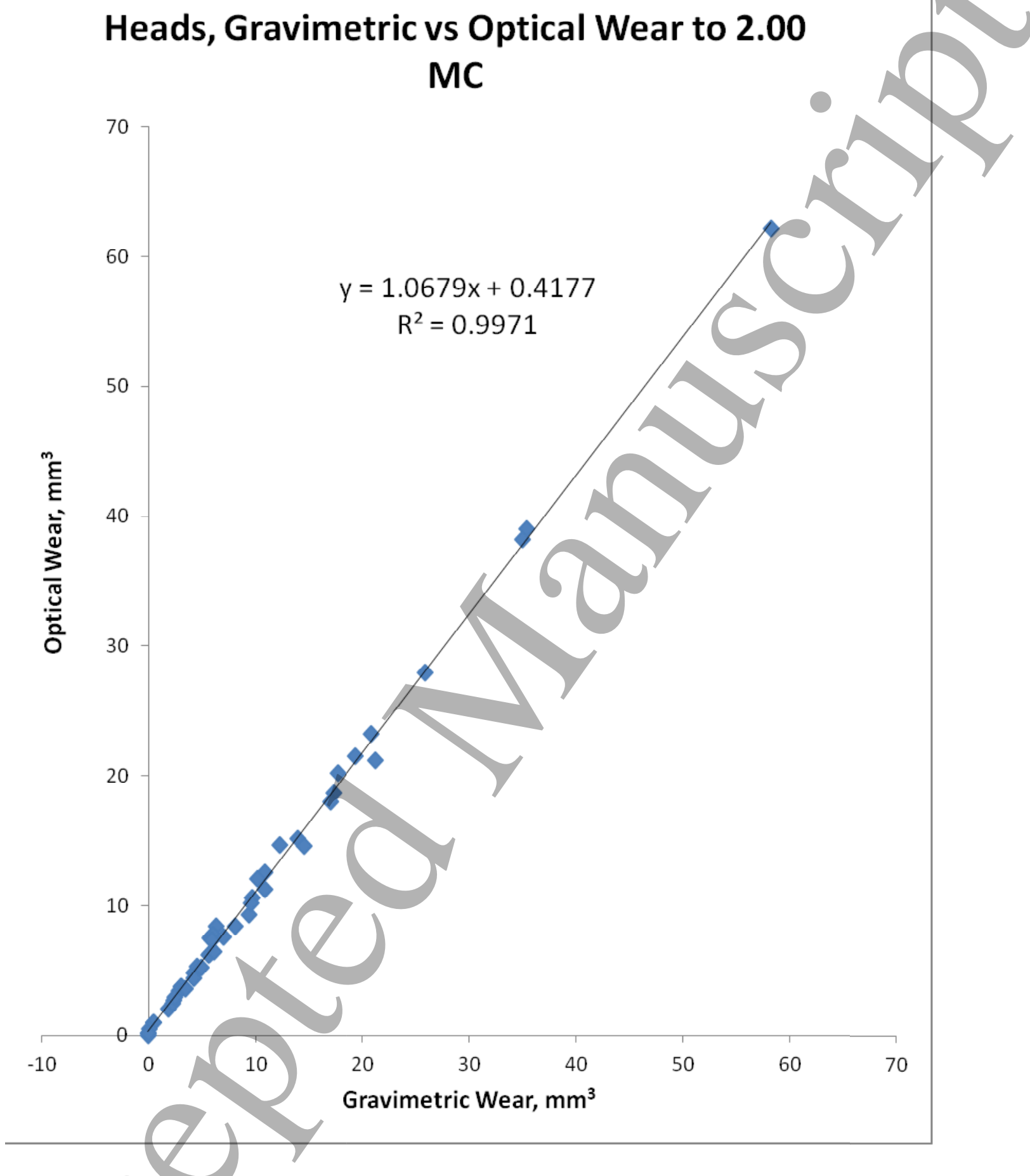

Figure 1. Volume loss measured optically versus gravimetrically for the heads. 


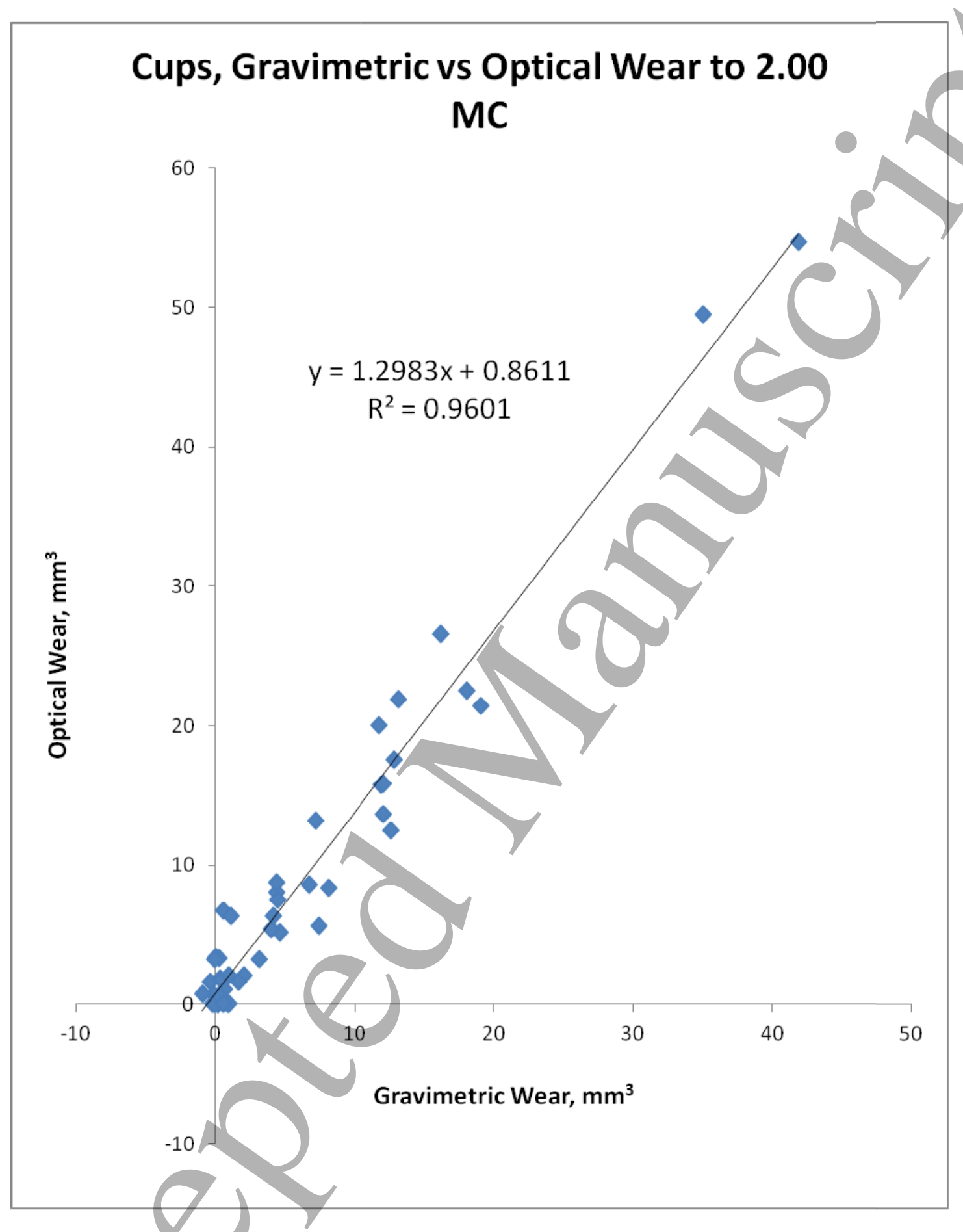

Figure 2. Volume loss measured optically versus gravimetrically for the cups. 

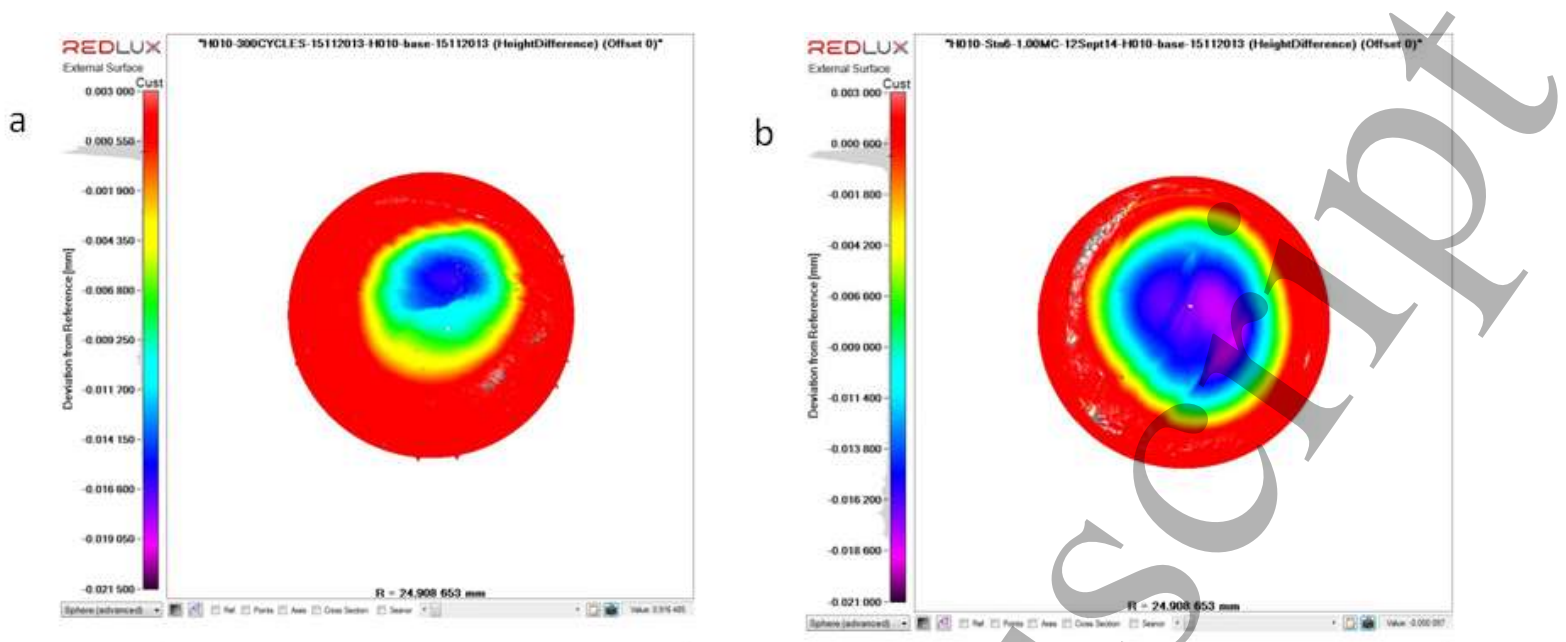

$\mathrm{C}$
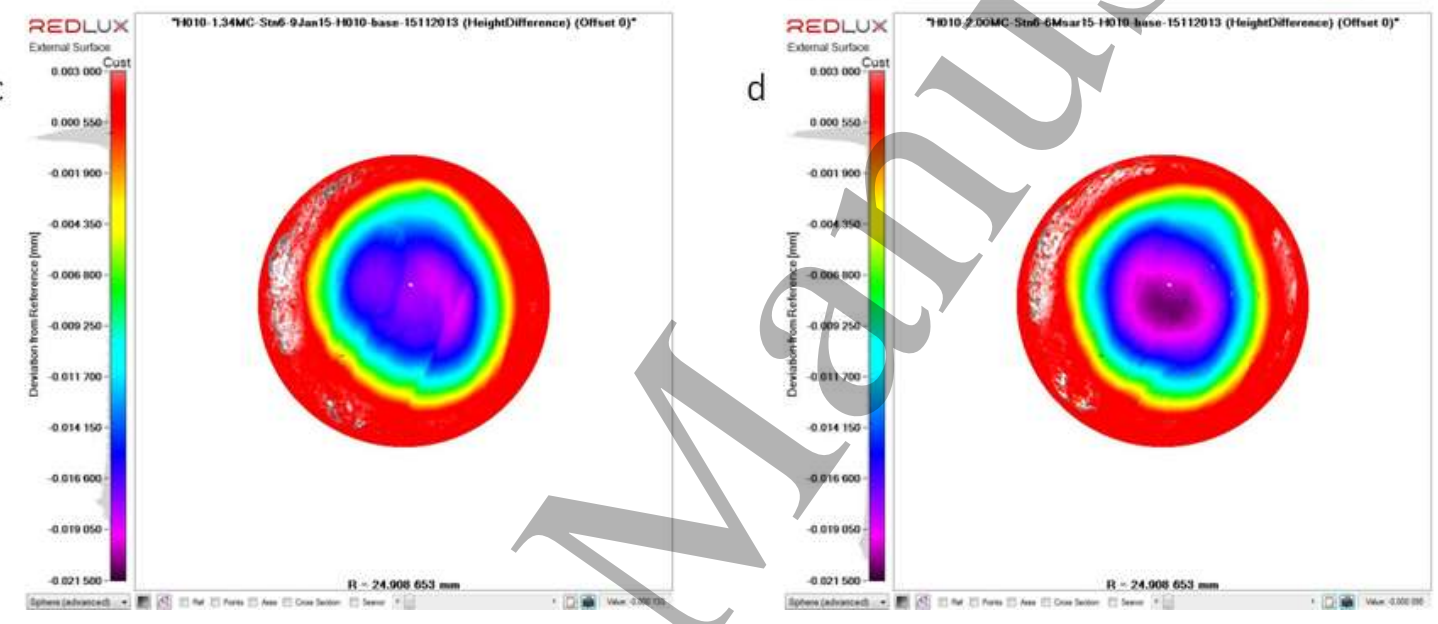

Figure 3. Progression of the wear scar and its depth from a representative head at a) $0.34 \mathrm{MC}, \mathrm{b}$ ) 1.00 MC, c) $1.34 \mathrm{MC}$ and d) $2.00 \mathrm{MC}$. White regions outside of the wear scar correspond to areas where tribofilm was observed. 

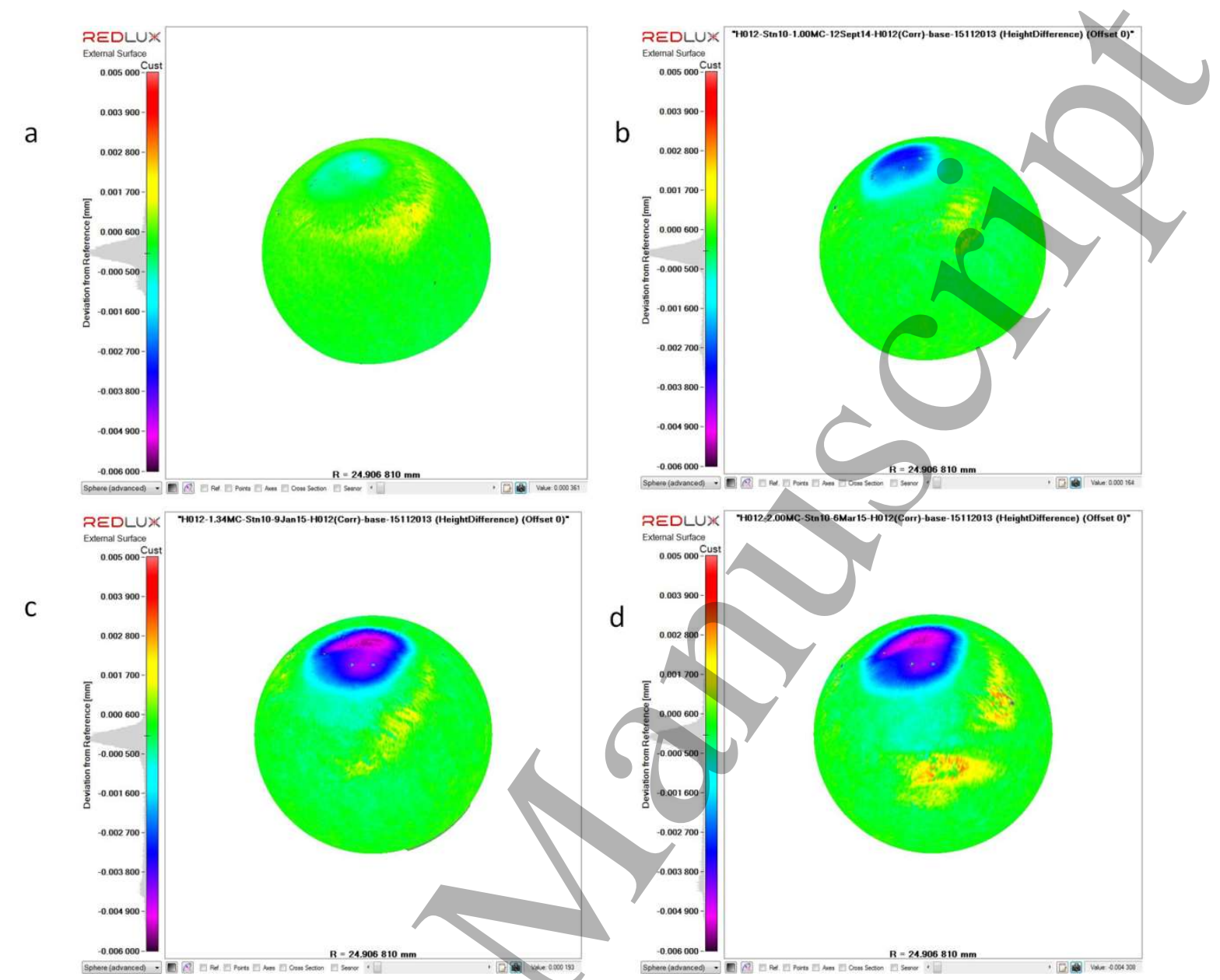

Figure 4. Progression of the wear scar and its depth from a low-wear head at a) $0.34 \mathrm{MC}, \mathrm{b}) 1.00$ $\mathrm{MC}, \mathrm{c}) 1.34 \mathrm{MC}$ and d) $2.00 \mathrm{MC}$. Yellow and red regions outside of the wear scar correspond to areas where tribofilm was observed.

\section{CMM and Optical measurements at $2 \mathrm{MC}(\mathrm{n}=9$ each $)$}

Volume loss at $2 \mathrm{MC}$ as measured by the optical method and by CMM is shown for the heads in Figure 5 and for the cups in Figure 6. For the heads, both geometric methods (optical and CMM) measured more volume loss than the gravimetric method (optical, $\mathrm{p}=0.004 ; \mathrm{CMM}$, $\mathrm{p}=0.08$ ). There was no statistically significant difference between the two methods in volume loss measured $(p=0.6)$ for the heads. 
For the cups, both methods measured significantly more volume loss than the gravimetric method (Optical, $\mathrm{p}=0.01 ; \mathrm{CMM}, \mathrm{p}=0.003)$ and the CMM measured more wear loss than the optical method $(\mathrm{p}=0.04)$. Two cups recorded negative wear at $2 \mathrm{MC}$ by the gravimetric method but none did by either the optical method or by CMM.

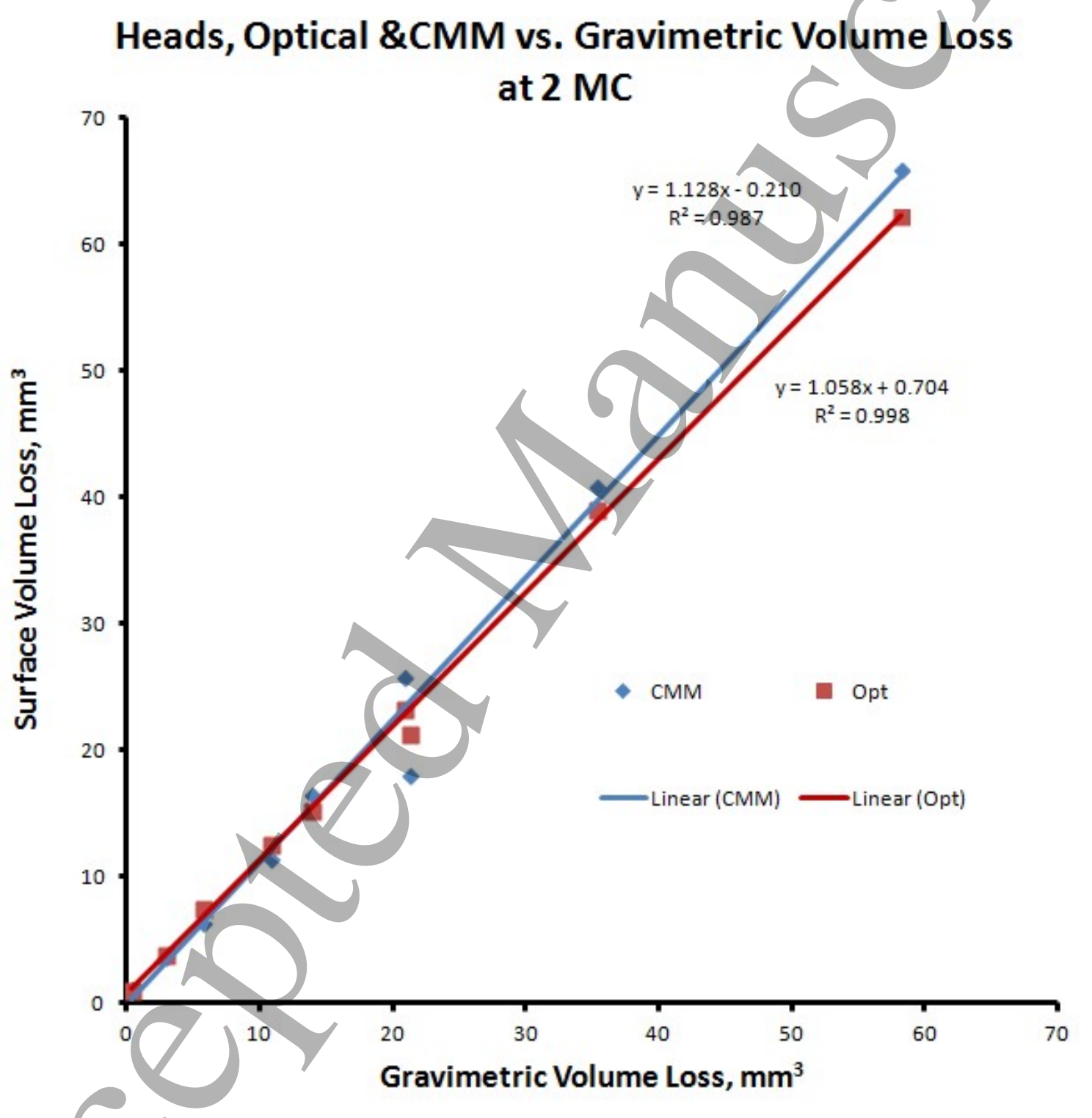

Figure 5. Volume loss in the heads measured by the optical method and CMM at $2 \mathrm{MC}$. 


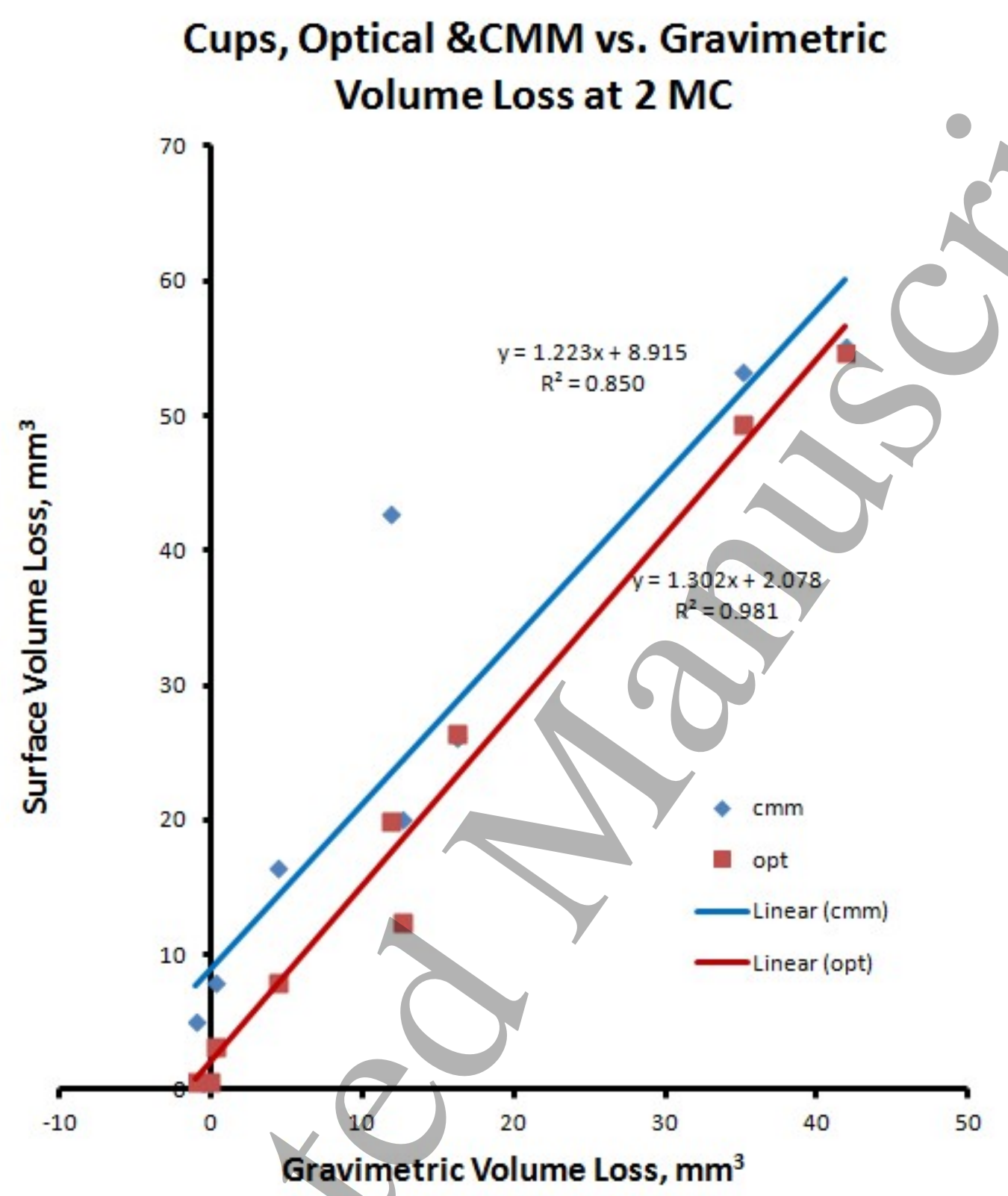

Figure 6. Nolume loss of the cups measured by the optical method and CMM at $2 \mathrm{MC}$. 


\section{DISCUSSION}

The simulator we used succeeded in providing us with the extremely wide range of MOM wear reported in the retrieval literature. The wear observed in the low wear stations resembled that observed in well functioning clinical retrievals. The surfaces of the high wear stations had some similarity to surfaces described by MeKellop et al $^{11}$ but did not match what we have seen in our retrievals. A 2006 review published wear rates that ranged from 0.03 to $3.1 \mathrm{~mm}^{3} / \mathrm{MC}$ for MoM simulator hip wear. ${ }^{20}$ However, simulator wear rates have too often failed to predict the wear found in retrieval studies. Lord et $\mathrm{al}^{21}$ found wear rates that ranged from 0.30 to 63.6 $\mathrm{mm}^{3} / \mathrm{MC}$ for cups and 0.52 to $95.5 \mathrm{~mm}^{3} / \mathrm{MC}$ for heads with a combined average of 22.66 $\mathrm{mm}^{3} / \mathrm{MC}$ in retrieved ASR hips (DePuy). Morlock et $\mathrm{al}^{22}$ reported a wear rate of $1.10 \mathrm{~mm}^{3}$ per year in retrievals that were normally aligned and did not show edge loading.

While this study cannot definitively say one surface method was better than the other, it does show that a surface measuring method when used in conjunction with the standard gravimetric method yields information that can be significant by providing information on surface wear that is much more quantitative than a visual inspection. It also demonstrated that it is feasible to add such a method with only a minimal delay in the time it takes to complete a wear simulation study. While the use of metal-on-metal implants is in steep decline, this technology can be applied to other materials such as polyethylene and ceramic. Surface changes in the polyethylene component of knee implants have shown that such changes affect the kinematics of the implant. ${ }^{8}$

Some kinetic and kinematic events that occur clinically, such as edge loading and intense impact from microseparation cannot be performed in simulation tests because they would tend to 
destroy the simulator during the $5 \mathrm{MC}$ the test is planned to complete. These sensitive surface methods may make it possible to study such destructive events by examining the surface damage left in short duration studies.

For both the heads and the cups, both the optical method and CMM tended to show more surface volume loss than could be accounted for by the gravimetric method. This could be due to protein absorption biasing the weight method or it could suggest plastic deformation of the surfaces is occurring. Such deformation has been shown to occur in polyethylene inserts ${ }^{23}$ and can occur in CoCrMo alloys. ${ }^{24}$ The load we used and the geometry of the Adept hips produces a theoretical Hertzian stress of $93.5 \mathrm{MPa}$, about $21 \%$ for the yield strength $(0.2 \%$ offset method $)$ required by ASTM F75.

Tuke et $\mathrm{al}^{14}$ used an abrasive method to remove material from the heads of MoM hips. They compared the optical method with the gravimetric method and obtained correlation results to the gravimetric similar to what we found for both the CMM and optical methods on the heads. However, they did not examine cup wear. Our data suggests that there may be a difference in accuracy between the CMM and optical methods in the cups.

There was a tendency for the CMM method to record significantly more material loss than both optical and gravimetric methods in some very low wear cups. In one cup, CMM measured over $8 \mathrm{~mm}^{3}$ of loss when gravimetrically wear was near zero and $3 \mathrm{~mm}^{3}$ optically. In another, it recorded $5 \mathrm{~mm}^{3}$ as opposed to negative wear gravimetrically and $0.7 \mathrm{~mm}^{3}$ material optically. Though it would never be included in a wear study, as a comparison of methods we did continue doing measurements for the excluded station that lost and burned lubricant prior to $1 \mathrm{MC}$. In that station at $2 \mathrm{MC}$, the head lost $66.60 \mathrm{~mm}^{3}$ by the gravimetric method, $63.36 \mathrm{~mm}^{3}$ by the CMM method and $60.69 \mathrm{~mm}^{3}$ by the optical method. For the cup, the gravimetric method measured 78.25, $\mathrm{mm}^{3}$, the CMM method $98.51 \mathrm{~mm}^{3}$ and the optical method $66.09 \mathrm{~mm}^{3}$ of loss. The optical method was 
not able to record any measurements in that hip unless it was changed to a 'ceramic' setting instead of a 'polished' setting.

In the cups, the higher deviations between the geometric and gravimetric data we believe are due to a couple of confounding factors; possible surface deformation and protein absorption on the beaded back. Surface deformation would tend to bias the geometric methods to measure more wear whereas protein absorption would bias the gravimetric method to underestimate wear. From preliminary studies we did with hips, we found that more vigorous scrubbing of the rough backside could by itself remove implant material. The use of a combination of geometric measurement and gravimetric measurements may help distinguish between material removal and surface deformation. 


\section{CONCLUSIONS}

The optical and CMM geometric measurement methods provide valuable information that cannot be obtained by the gravimetric method alone; the total wear area, its location, its depth profile and isolation of bearing surface changes from the backside wear. With automation, the surface methods allowed each surface scan to be performed in minutes making it possible to monitor the progression of the wear scar with each weighing procedure. Unlike visual observation, the geometric methods provide quantitative information and a 3-D record that can be tracked over time and perhaps projected beyond the duration of the test. Such tracking may be used to estimate the direction and amount of wear beyond the test duration and provide more reliable values for extremely low wear allowing for improved patient outcomes through longer lasting implants.

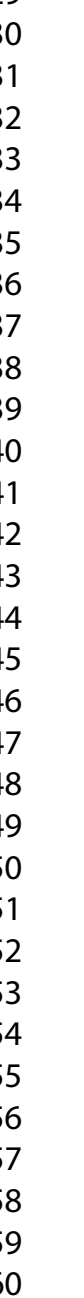




\section{ACKNOWLEDGEMENTS}

We would like to acknowledge Mike Tuke of MatOrtho for the generous donation of ten Adept hips.

Richard Baker Cook has received research support from Biomet; Paul Bills has been a paid consultant for DePuy Synthes and Johnson \& Johnson, an unpaid consultant for Stryker, Zimmer Biomet and Corin and received research support from DePuy Synthes and Zimmer Biomet; Radu Racasan has been a paid consultant for DePuy Synthes. No disclosures for the other authors. 


\section{REFERENCES}

1. Dowson D, Hardaker C, Flett M, et al. A hip joint simulator study of the performance of metal-on-metal joints part II: design. J Arthroplasty 2004; 19(8 Suppl. 3):124-30.

2. Campbell P, Ebramzadeh E, Nelson S, et al. Histological features of pseudotumor-like tissues from metal-on-metal hips. Clin Orthop Relat Res 2010; 468(9):2321-7.

3. Rising JP, Reynolds IS, and Sedrakyan A. Delays and Difficulties in Assessing Metal-onMetal Hip Implants N Engl J Med 2012; 5; 367(1):e1.

4. Smith AJ, Dieppe P, Vernon K, et al on behalf of the National Joint Registry of England and Wales. 2012. Failure rates of stemmed metal-on-metal hip replacements: analysis of data from the National Joint Registry of England and Wales. Lancet 2012; 379: 1199-204.

5. Smith AJ, Dieppe P, Howard PW, et al. On behalf of the National Joint Registry for England and Wales. 2012 Failure rates of metal-on-metal hip resurfacings: analysis of data from the National Joint Registry for England and Wales. Lancet 2012; 380: 1759-66.

6. Al-Hajjar M, Fisher J, Williams S, et al. Effect of femoral head size on the wear of metal on metal bearings in total hip replacements under adverse edge-loading conditions. $J$ Biomed Mater Res Part B 2013:101B:213-222. 
7. Joyce T, Langton DJ, Jameson SS et al. Tribological analysis of failed resurfacing hip prostheses and comparison with clinical data. J Engineering Tribology 2009, 317-323.

8. Williams, JL, Knox DA, Teeter MG, et al. Evidence that in vivo wear damage alters kinematics and contact stresses in a total knee replacement. J. Long-Term Effects of Med. Implants 2010; 20(1):43-48.

9. Underwood RJ, Zografos A, Sayles RS, et al. Edge loading in metal-on-metal hips: low clearance is a new risk factor. Proc Inst Mech Eng H 2012; 226(3):217-26.

10. Jayabalan P, Furman BD, Cottrell JM, et al. Backside wear in modern total knee designs. HSS J 2007; 3(1):30-4.

11. McKellop H, Park S, and Chiesa R. In vivo wear of three types of metal on metal hip prothesis during 2 decades of use, Clinical Orthopaedic Rel Res 1996; 329S:128-140.

12. ASTM F75. Standard Specification for Cobalt-28 Chromium-6 Molybdenum Alloy Castings and Casting Alloy for Surgical Implants (UNS R30075) ASTM International, West Conshohocken, PA, 2012.

13. ASTM F1714. Standard Guide for Gravimetric Wear Assessment of Prosthetic Hip Designs in Simulator Devices. ASTM International, West Conshohocken, PA, 1996 (Reapproved 2008). 
14. Tuke M, Taylor A, Roques A, et al 3D linear and volumetric wear measurement on artificial hip joints_-Validation of a new methodology. Precision Engineering 2010; 34: 777-783.

15. Bills PJ, Racasan R, Underwood RJ, etal. Volumetric wear assessment of retrieved metalon-metal hip prostheses and the impact of measurement uncertainty, Wear 2010; 274: 212-219.

16. Matthies A, Racasan R, Bills P, et al. Material Loss at the Taper Junction of Retrieved Large Head Metal-on-Metal Total Hip Replacements. Journal of Orthopaedic Research 2013; 31 (11), pp. 1677-1685.

17. Whittaker R, Hexter A, Hothi H, et al. Component Size Mismatch of Metal on Metal Hip Arthroplasty: An Avoidable Never Event. Journal of Arthroplasty 2014; 29 (8): 1629-1634.

18. ASTM F2979-14, Standard Guide for Characterization of Wear from the Articulating Surfaces in Retrieved Metal-on-Metal and other Hard-on-Hard Hip Prostheses, ASTM International, West Conshohocken, PA, 2014.

19. Hesketh J, Ward M, Dowson D, et al. The composition of tribofilms produced on metal-onmetal hip Bearings. Biomaterials 2014; 35(7):2113-9.

20. Scholes C and Unsworth A. The tribology of metal-on-metal total hip replacements. Proc Ins Mech Eng H 2006; 220: 183-94. 
21. Lord JK, Langtona DJ, Nargol AVF, et al. Volumetric wear assessment of failed metal-onmetal hip resurfacing prostheses. Wear 2011; 272:79-87.

22. Morlock MM, Bishop ND, Zustin J, et al. Modes of Implant Failure After Hip Resurfacing: Morphological and Wear Analysis of 267 Retrieval Specimens. J Bone Joint Surg Am 2008; 90 Supp1 3: 89-95.

23. Bali K, Naudie DD, Howard JL, et al. Comparison of Tibial Insert Polyethylene Damage in Rotating Hinge and Highly Constrained Total Knee Arthroplasty: A Retrieval Analysis. $J$ Arthroplasty 2016; 31(1):290-4.

24. Yang S, Dillon OW Jr, Puleo DA, et al. Effect of cryogenic burnishing on surface integrity modifications of Co-Cr-Mo biomedical alloy. J Biomed Mater Res B Appl Biomater 2013; 101(1):139-52. 


\section{Figure Legends}

Figure 1. Volume loss measured optically versus gravimetrically for the heads.

Figure 2. Volume loss measured optically versus gravimetrically for the cups.

Figure 3. Progression of the wear scar and its depth from a representative head at a) $0.34 \mathrm{MC}, \mathrm{b}$ ) 1.00 MC, c) 1.34 MC and d) 2.00 MC. White regions outside of the wear scar correspond to areas where tribofilm was observed.

Figure 4. Progression of the wear scar and its depth from a low-wear head at a) $0.34 \mathrm{MC}, \mathrm{b}) 1.00$ $\mathrm{MC}$, c) 1.34 MC and d) 2.00 MC. Yellow and red regions outside of the wear scar correspond to areas where tribofilm was observed.

Figure 5. Volume loss in the heads measured by the optical method and CMM at $2 \mathrm{MC}$.

Figure 6. Volume loss of the cups measured by the optícal method and CMM at $2 \mathrm{MC}$. 